\title{
Long-term creep behavior of self-reinforced PET composites
}

\author{
C. M. Wu* P. C. Lin, R. Murakami \\ Department of Materials Science and Engineering, National Taiwan University of Science and Technology, 10607 Taipei, \\ Taiwan, R.O.C.
}

Received 3 March 2017 accepted in revised form 14 May 2017

\begin{abstract}
Creep deformation of polymers results from their inherent viscoelastic nature that changes polymer's shape with time. Creep response represents an important property of thermoplastic composites that affects their dimensional stability, especially in applications requiring the material ability to support relatively high loads for long periods. This work examines the creep behavior of self-reinforced recycled poly(ethylene terephthalate) (srrPET) composites, which were produced by film stacking from fabrics composed of double covered uncommingled yarns with recycled PET homopolymer filaments (serving as the reinforcements) and copolymerized PET (mPET) filaments (serving as the matrix). The short-term creep behavior of both srrPET and mPET was studied in the single cantilever mode below and above the glass transition temperature, and the obtained data were analyzed using the Findley's viscoelastic and Burgers four-element models. The long-term creep behavior of srrPET specimens with and without open circular holes was described using an Arrhenius-type time-temperature superposition principle.
\end{abstract}

Keywords: polymer composites, self-reinforced PET composites, creep behavior, time-temperature superposition principle

\section{Introduction}

The modern lifestyle supported by advanced manufacturing technologies produces increasing quantities of polymeric waste materials, which create severe disposal problems. The latter can be alleviated by either improving the current methods for recycling and reusing the existing materials or developing new and intrinsically more suitable composites. Significant efforts have been made to develop polymer composites that can be easily reprocessed by melting. Self-reinforced polymer composites (srPCs, which are also called single-polymer or all-polymer composites) represent an effective alternative to the traditional fiber-reinforced composites since both their matrices and reinforcements are fabricated from the same polymer, thereby facilitating their recyclability [1-4].

Self-reinforced polypropylene (srPP) composites have been intensively studied and are commercially available as the Curv ${ }^{\mathrm{TM}}$ and PURE ${ }^{\circledR}$ brands. They are currently utilized for manufacturing automotive components, luggage, sporting, and protective goods, and their flame retardation properties attracted significant interest [5]. However, the thermal stability and related service temperatures of srPP composites are relatively low; therefore, various attempts have been made to develop srPC-based materials from high temperature polymers [4] such as polyethylene terephthalate (PET) [6-8] (for example, PET-based soft drink bottles can be easily converted to textile fibers using a simple recycling procedure [9]). Many currently manufactured textile products already contain recycled PET (rPET) fibers, and their use for the development of novel srPC composites fits the described 'upcycling' strategy relatively well. Hybrid or commingled yarns can also be used as suitable preforms of srPET composites since they can be processed on the existing industrial lines and, therefore, easily

\footnotetext{
*Corresponding author, e-mail: cmwu@mail.ntust.edu.tw C) BME-PT
} 
converted to different textile architectures $[10,11]$. Co-wrap spinning commingled methods were also utilized to successfully prepare self-reinforced recycled PET (srrPET) composites in the authors' laboratory from the $\mathrm{rPET} /$ copolymerized PET (mPET) commingled yarns [12-15], and their open-hole tensile properties [14], fracture behavior, and damage development [13] have been recently investigated. Bilinear elastic-ductile characteristics were observed during open-hole tensile testing, which revealed that srrPET composites exhibited superior ductile behavior and were insensitive to notches [14]. The presence of plastic deformation in the vicinity of the hole reduce the stress concentration. In addition, srrPET composites exhibited higher resistance to crack initiation and propagation as compared to that of flameretarded srrPET, indicating that the former were tough, ductile, and notch-insensitive materials with superior load-carrying characteristics.

When a plastic material supports large loads for prolong periods, it deforms continuously with time. Such time-dependent deformation of materials (often called viscoelastic behavior or creep) represents an important property of fiber-reinforced polymers, which allows better understanding of their structure-property relationship. The long-term durability of composites is essential for estimating their lifetimes under load. The creep rupture of a polymer results from the combination of various factors including viscoelastic deformation, primary and secondary bond rupture, shear yielding and crazing, chain slippage, void formation and growth, and fibril breakdown due to the presence of intrinsic and extrinsic flaws. Additionally, the polymer/fiber and particle interfacial strengths as well as temperature, stress, and time also affect the creep response of polymeric and polymer composite materials. The creep behavior of traditional carbon fiberreinforced and glass fiber-reinforced composites have been extensively studied [16-19]; however, the creep deformation of srPCs represents a more complex phenomenon than since both their matrices and reinforcements are fabricated from the same polymer. Several studies on the properties of srPP composites revealed that their creep behavior strongly depended on various parameters including stress, temperature, void content, fiber loading, lay-up structure, and crystallinity [20-23]. It has been also reported that creep resistance decreases with increasing temperature or stress and increases with increasing material consolidation (which lowers the overall void content).
Since studying the creep behavior of materials requires relatively long times, possible methods for extrapolating the long-term creep behavior from the data obtained during short-term testing has attracted considerable attention. One of the most commonly used extrapolation techniques is represented by the time-temperature superposition principle (TTSP), which utilizes real-time short-term creep responses obtained at elevated temperatures. Although TTSP was initially used only for pure polymers, numerous studies have utilized this principle to predict the long-term creep behavior of carbon-, glass-, and natural fiber-reinforced composites [24-29]. Due to the aging of the polypropylene matrix with time, TTSP successfully predicted the long-term creep response of polymer composites at ambient temperature, but was found to be unsuitable at higher temperatures [30]. The long-term creep behavior of srPP composites was studied by Izer and Bárány [31] and KargerKocsis and covorkers $[32,33]$ using TTSP, who concluded that it could be satisfactorily described by an Arrhenius-type relationship. However, in spite of the recent progress in investigating the creep behavior of fiber-reinforced composites, limited results were obtained for srPCs (especially for srPET-based materials).

During manufacturing of composite parts, hole drilling is typically used to provide access to joints or facilitate their fabrication. However, holes also act as stress concentrators and thus disturb the stress distribution inside the material. Owing to the stress concentration near the holes, the increasing load initiates damage, which propagates in the hole vicinity and ultimately leads to early material failure. Hence, the results obtained during open-hole creep testing may be used for evaluating the material structural reliability.

In this work, the creep performance of srPET composites with and without flame retardant has been studied. Two different materials were investigated: pure srrPET composite and srrPET composite with flame retardant (srrPET-FR), which was more prone to interphase- and matrix-related debonding [14]. Typically, srrPET composites exhibit higher resistances to crack initiation and growth as compared to those of srrPET-FR materials. The effects of the fiber/ matrix bonding strength, presence of circular holes, and temperature on the creep behavior of srrPET composites were examined, and the applicability of the TTSP method for predicting their long-term creep 
response from the obtained short-term creep testing data was evaluated.

\section{Experimental}

\subsection{Materials}

The recycled PET multifilament (sPET) and flameretarded (FR) PET multifilament (rPET-FR) bundles with tenacities of $65.4 \mathrm{~g} / \mathrm{tex}$ and $58.3 \mathrm{~g} /$ tex and elongations of 25.3 and $27.4 \%$, respectively, were used as the reinforcements (each individual multifilament bundle contained 192 filaments) [13, 14]. PET copolymer yarns with and without FR (mPET-FR and mPET, respectively) served as the matrices of the corresponding self-reinforced PET composites (they consisted of 35.6 tex multifilament bundles with tenacities of 42.8 and $21.6 \mathrm{~g} / \mathrm{tex}$ and elongations of 27.9 and $34.1 \%$, respectively) $[13,14]$. The utilized mPET and mPET-FR bundles contained 96 and 72 filaments, respectively. Two major melting peaks were observed at 238 and $262^{\circ} \mathrm{C}$ for rPET yarns, while the melting temperature of $\mathrm{mPET}$ yarns was equal to $226^{\circ} \mathrm{C}$. The concentration of phosphorous flame retardant in the composite matrix was set to $0.55 \% \mathrm{w} / \mathrm{w}$.

\subsection{Preparation of self-reinforced PET composites}

The original rPET and mPET yarns were combined to produce double covered uncommingled yarns (DCUY) using a hollow spindle spinning machine (here rPET yarn was used as the core yarn, and mPET yarn represented the binding yarn). The main spinning parameters were the number of turns (694 turns $/ \mathrm{m})$, rotation speed (5500 rpm), and yarn output $(7.93 \mathrm{~m} / \mathrm{min})$. To achieve even distribution of the reinforcing PET fibers, their volume fraction in the DCUY preform was set to around $53 \%$. The obtained DCUY was used as a feed material for producing $2 / 2$ basket-woven fabric (the co-wrap spinning yarns serving as the warp and weft yarns were woven on a rapier weaving machine). The densities of the wrap and weft yarns were 13.4 and 11.8 bundles/cm, respectively.

Pieces of srrPET and srrPET-FR fabrics with dimensions of $1 \mathrm{~m} \times 1 \mathrm{~m}$ were fabricated using an industrial hot press (FC-650TON, Long Chang, Taiwan). srrPET composites were prepared by stacking five layers of the basket fabrics and subjecting them to the $12 \mathrm{MPa}$ pressure at a temperature of $235^{\circ} \mathrm{C}$ for $1 \mathrm{~min}$ followed by fast cooling. The thickness of the resulting
srrPET sheets was $2 \mathrm{~mm}$, while their void content determined via density measurements (ASTM D2734) was below 1\%. For comparison purposes, mPET specimens were prepared by hot pressing $\mathrm{mPET}$ flakes at a pressure of $12 \mathrm{MPa}$ and temperature of $235^{\circ} \mathrm{C}$ for $1 \mathrm{~min}$. The limiting oxygen index (ASTM D2863) values of the produced srrPET and srrPETFR composites were 26.6 and $35.3 \%$, while their UL-94 ratings (ASTM D2863, vertical burning) were V-1 and V-0, respectively.

\subsection{Dynamic mechanical analysis}

Dynamic mechanical analysis (DMA) was performed using a TA Q800 dynamical mechanical analyzer. The obtained specimens with dimensions of $17.5 \mathrm{~mm} \times 12.8 \mathrm{~mm} \times 2 \mathrm{~mm}$ (Figure 1) were cut along the longitudinal direction of the warp PET yarns. Experiments were conducted in the single cantilever mode under isochronal conditions corresponding to frequencies of $1-40 \mathrm{~Hz}$, strain amplitude of $20 \mu \mathrm{m}$, temperatures between 40 and $200^{\circ} \mathrm{C}$, and scanning rate of $3{ }^{\circ} \mathrm{C} / \mathrm{min}$.

Flexural creep measurements were performed using a single cantilever loaded in the creep mode at a temperature of $35^{\circ} \mathrm{C}$, durations of $60 \mathrm{~min}$, and stress of $10 \mathrm{MPa}$. As shown in Figure 2, the selected stress levels were below the yield stress of the studied srrPET composites. Therefore, the effect of the viscoelastic strain on the material creep behavior could be considered negligible.

To study the effect of the open circular holes on the creep behavior of srrPET composites, flexural creep experiments were performed. The circular holes were drilled in the specimen centers using modified hollow-cylindrical steel drilling bits (they were machined by initially drilling starter holes with smaller
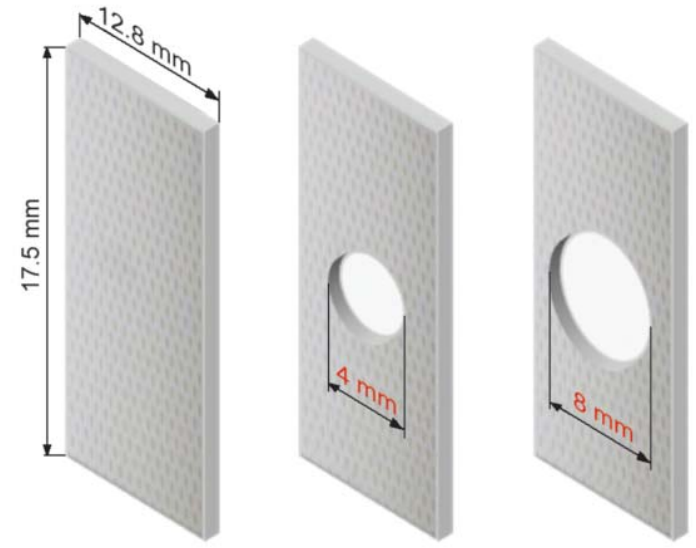

Figure 1. Open-hole flexural creep specimens with different hole sizes 
diameters followed by their gradual enlargement to the final dimensions via incremental drilling). To avoid delamination at the hole edges, a flat wooden plate was clamped below the specimen. The notched region was hand-polished using sand paper. Circular holes with diameters of 4 and $8 \mathrm{~mm}$ (Figure 1) were used during open-hole creep testing.

\subsection{Short-term creep behavior and TTSP model}

To analyze the creep behavior of srrPET composites, the four-parameter Burgers and Findley's models were used $[22,34]$. The generalized Burgers viscoelastic model consisted of one Maxwell element and one Kelvin-Voigt element connected in series. According to this model, the total creep strain can be described by the Equation (1):

$$
\varepsilon=\frac{\sigma}{E_{1}}+\frac{\sigma}{E_{2}}\left(1-\exp \left(-t \frac{E_{2}}{\eta_{2}}\right)\right)+t \frac{\sigma}{\eta_{1}}
$$

where $\varepsilon$ is the total strain accumulated after time $t$ under the applied stress $\sigma . E_{1}$ and $E_{2}$ are the elastic moduli of the springs of the Maxwell and KelvinVoigt elements, respectively, while $\eta_{1}$ and $\eta_{2}$ represent the corresponding dashpot viscosities. Findley's power law model can be expressed as shown by by the Equation (2):

$$
\varepsilon(t)=\varepsilon_{0}+A t^{\mathrm{n}}
$$

where $\varepsilon(t)$ is the time-dependent creep strain, $\varepsilon_{0}$ is the instantaneous elastic strain, $A$ is the amplitude of the transient creep strain, and $n$ is the constant. All constants utilized in the Findley's model were determined by applying the curve fitting procedure of the Origin 8 software.

To characterize the viscoelastic behavior of the studied composites over a wide range of frequencies (or times), TTSP were applied at several temperatures, and the obtained short-term experimental data points were shifted empirically towards the value corresponding to the reference temperature on a semi-log axis to construct a master curve. According to the TTSP, a given property evaluated after short periods at a higher temperature would be identical to that evaluated after longer times at a lower temperature after the corresponding curve is shifted along the horizontal axis to match the master curve.

By applying the TTSP, real-time short-term creep responses at elevated temperatures can be used to predict the long-term creep performance of composites.
Each short-term creep testing procedure was conducted up to five times using the same parameters, and the obtained results were fitted to construct a suitable plot of strain versus time. Thus, short-term creep testing was performed at elevated temperatures $\left(40-200^{\circ} \mathrm{C}\right)$, and the reference temperature was set to $40^{\circ} \mathrm{C}$; as a result, the obtained short-term creep curves were shifted horizontally on a log scale using a shift factor. Both the William-Landel-Ferry (WLF) and Arrhenius equations were used to obtain the shift factors for polymer composites in previous studies. For srPP, the Arrhenius equation was found to generate better fitting results as compared to the data produced by the WLF equation [31-33]. The WLF equation was found empirically to describe the frequency dependence of glass transition temperature in amorphous polymers. For the temperature range below the glass transition temperature, the Arrhenius equation is generally acknowledged as suitable to describe the relationship between the shift factors of the master curve and the temperature. Therefore, the Arrhenius equation was used to estimate the shift factors in this study. Their magnitudes can be related to the specimen temperature and activation energy via the Equation (3):

$\log \alpha_{\mathrm{T}}=\frac{E_{\mathrm{a}}}{R}\left(\frac{1}{T}-\frac{1}{T_{\text {ref }}}\right) \log \mathrm{e}$

where $\alpha_{\mathrm{T}}$ is the shift factor, $E_{\mathrm{a}}$ is the activation energy $[\mathrm{kJ} / \mathrm{mol}], T_{\text {ref }}$ is the reference temperature $[\mathrm{K}], T$ is the experimental temperature $[\mathrm{K}]$, and $R$ is the universal gas constant, $8.314 \mathrm{~kJ} / \mathrm{mol}$.

The value of $E_{\mathrm{a}}$ was estimated from the frequency dependence of the glass transition temperature $\left(T_{\mathrm{g}}\right)$ of srrPET composites (it represents the energy barrier that must be overcome to initiate the molecular motions causing the glass transition relaxation). The magnitudes of $T_{\mathrm{g}}$ at different frequencies were determined via DMA, and the $E_{\mathrm{a}}$ of creep deformation was calculated from the slope of the plot of $\ln f$ (natural logarithm of frequency) versus $1 / T_{\mathrm{g}}$ using the Equation (4):

$E_{\mathrm{a}}=-R \frac{\mathrm{d}(\ln f)}{\mathrm{d}\left(\frac{1}{T_{\mathrm{g}}}\right)}$

After substituting the obtained value of $E_{\mathrm{a}}$ into Equation (1), the corresponding shift factor was estimated at a given experimental temperature. The creep strain curves plotted at elevated temperatures were shifted 
to the right using the shift factors, while the curve corresponding to the reference temperature $\left(40^{\circ} \mathrm{C}\right)$ remained intact. The resulting master curve represented the long-term strain periods of srrPET composites measured at a temperature of $40^{\circ} \mathrm{C}$.

\section{Results and discussion}

\subsection{Dynamic mechanical properties}

Dynamic mechanical measurements are usually performed over a wide temperature range to examine the viscoelastic behavior of polymers and related composites and provide valuable insights into the relationship between their structure, morphology, and properties. Figure $2 \mathrm{a}$ shows the magnitudes of $\tan \delta$ for mPET and srrPET composites plotted at various temperatures. A broad relaxation peak was observed at $130^{\circ} \mathrm{C}$ for srrPET, whereas the $\alpha$ transition peak $\left(T_{\alpha}\right)$ was detected for mPET at $90^{\circ} \mathrm{C}$. The shift of $T_{\alpha}$ to higher temperatures observed for srrPET can be attributed to strong interfacial bonding between the reinforcing rPET fibers and the mPET matrix [13], which produced a structure characterized by high integrity. In contrast, two relaxation peaks detected at 85 and $117^{\circ} \mathrm{C}$ for srrPET-FR composite corresponded to the $\alpha$ transitions of the mPET matrix and reinforcing PET fibers, respectively. The reason for the appearance of a double peak is the phase separation, which results from relatively poor interfacial bonding between the rPET reinforcements and the MPET matrix [13]. It should be also noted that the maximum value of $\tan \delta$ (around 0.24) obtained for mPET was much higher than that of srrPETs (around 0.14), indicating that the creep resistance of $\mathrm{mPET}$ could be significantly enhanced by the addition of reinforcing rPET fibers. As shown in Figure 2b, the storage modulus of srrPETs in the glassy state was relatively high (around

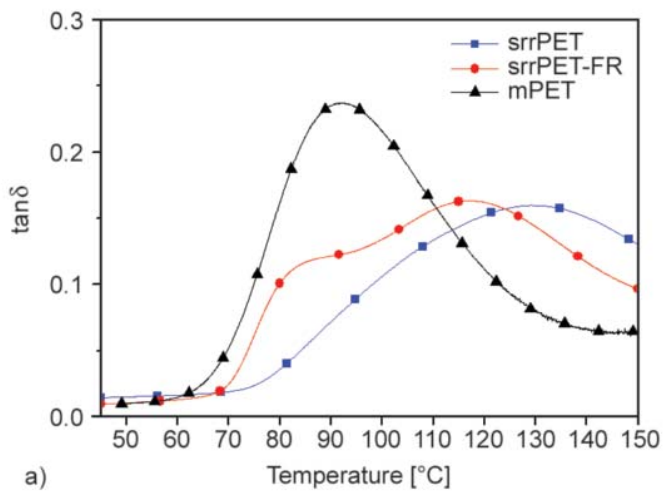

3.2 $\mathrm{GPa}$ ) as compared to the magnitude obtained for pure $\mathrm{mPET}$ (around $2.7 \mathrm{GPa}$ ) at temperatures below $70^{\circ} \mathrm{C}$. After increasing temperature above $70^{\circ} \mathrm{C}$, the storage moduli of srrPET and mPET were significantly reduced. Although srrPET composite lost a great share of its elastic response above this temperature, its residual storage modulus $E^{\prime}$ at $100{ }^{\circ} \mathrm{C}$ was still much higher (around $1 \mathrm{GPa}$ ) than that of mPET (around $0.4 \mathrm{GPa}$ ), which suggested that the studied materials became susceptible to deformation. Such large values of the storage modulus can be attributed to the presence of highly oriented crystals and polymer chains originated from the high draw ratio of reinforcing fibers (very little difference in the $E^{\prime}$ response was observed between srrPET and srrPET-FR composites).

As have been discussed previously in Section 2.4, $T_{\mathrm{g}}$ represents an important parameter describing the longterm creep behavior of a material (glass transition is usually accompanied by an abrupt decrease in the modulus and occurs over a range of temperatures). Therefore, a particular value of $T_{\mathrm{g}}$ may vary significantly depending on the utilized computational method. It has been found that in order to study the mechanical properties of a material, the magnitude of $T_{\mathrm{g}}$ based on $E^{\prime}$ and calculated from the intersection of two tangent lines should be used, whereas the $T_{\mathrm{g}}$ based on $\tan \delta$ is more appropriate for chemical analysis [35]. Therefore, in this study, the $T_{\mathrm{g}}$ values of srrPET, srrPET-FR, and mPET were determined at a frequency of $1 \mathrm{~Hz}$ and temperatures of 69.3, 68.9 , and $67.3^{\circ} \mathrm{C}$, respectively (see Figure $2 \mathrm{~b}$ ).

\subsection{Short-term creep behavior}

The results of flexural creep testing of srrPET composites and mPET performed at $35^{\circ} \mathrm{C}$ are shown in

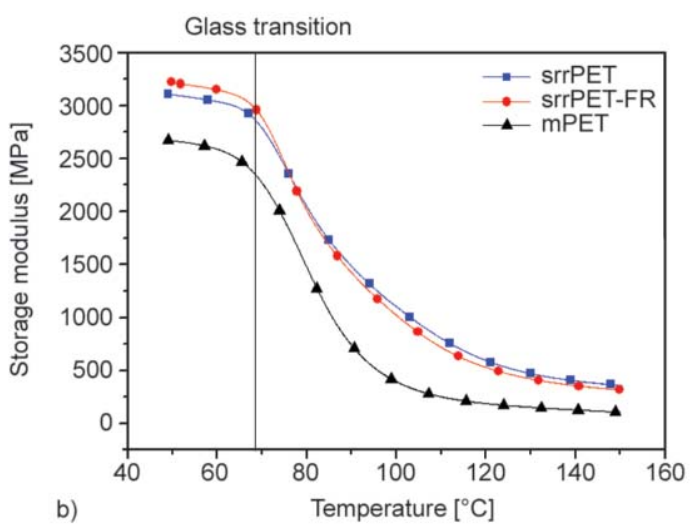

Figure 2. DMA plots of (a) tan $\delta$ and (b) storage modulus versus temperature obtained for the srrPET and mPET specimens at a frequency of $1 \mathrm{~Hz}$ 


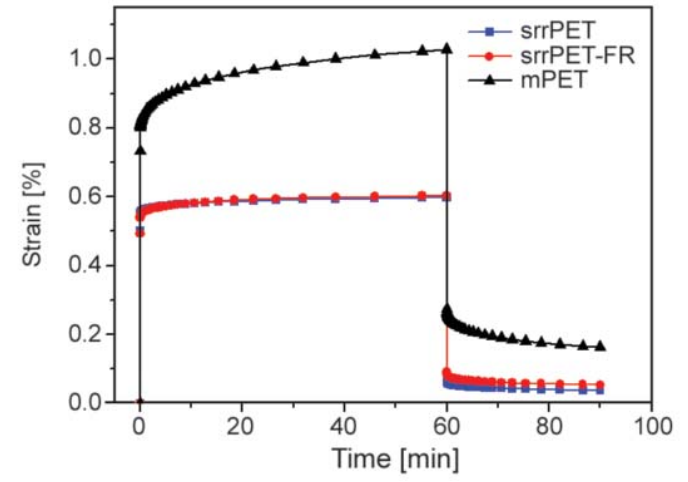

Figure 3. Short-term creep responses of the srrPET and mPET specimens

Figure 3. The obtained results indicate that the strain of srrPET was much lower than that of mPET. In particular, the instantaneous strain of srrPET was equal to $0.54 \%$, which gradually increased to $0.6 \%$ after $1 \mathrm{~h}$ (the corresponding magnitudes measured for $\mathrm{mPET}$ were 0.8 and $1.0 \%$, respectively). Hence, self-reinforced polymer composites (srPET) exhibit significantly higher resistance to creep deformation as compared to that of pure polymeric materials (mPET) due to the higher rigidity of reinforcing fibers (rPET).

To further analyze the obtained results of short-term creep testing, the Findley's and Burgers models were utilized. A generalized Burgers viscoelastic model was used to describe the short-term creep responses of srrPET composites and mPET (the utilized mathematical expression is presented in Equation (1), and its constants determined via curve fitting on the creep strain and recovery strain curves are listed in Table 1). The values of $A$ and $n$ of Findley's power law were obtained for srrPET composites and mPET using Equation (2) and listed in Table 1. According to the data listed in Table 1, both these parameters were higher for mPET than for the other two srrPET composite materials. As indicated by Equation (2), higher values of $A$ and $n$ increase the creep strain of the material. The fitted parameters, summarized in Table 1, were used to generate the curves for the shortterm creep results in Figure 4 (solid lines). For all tested PET samples, Findley's power law model could
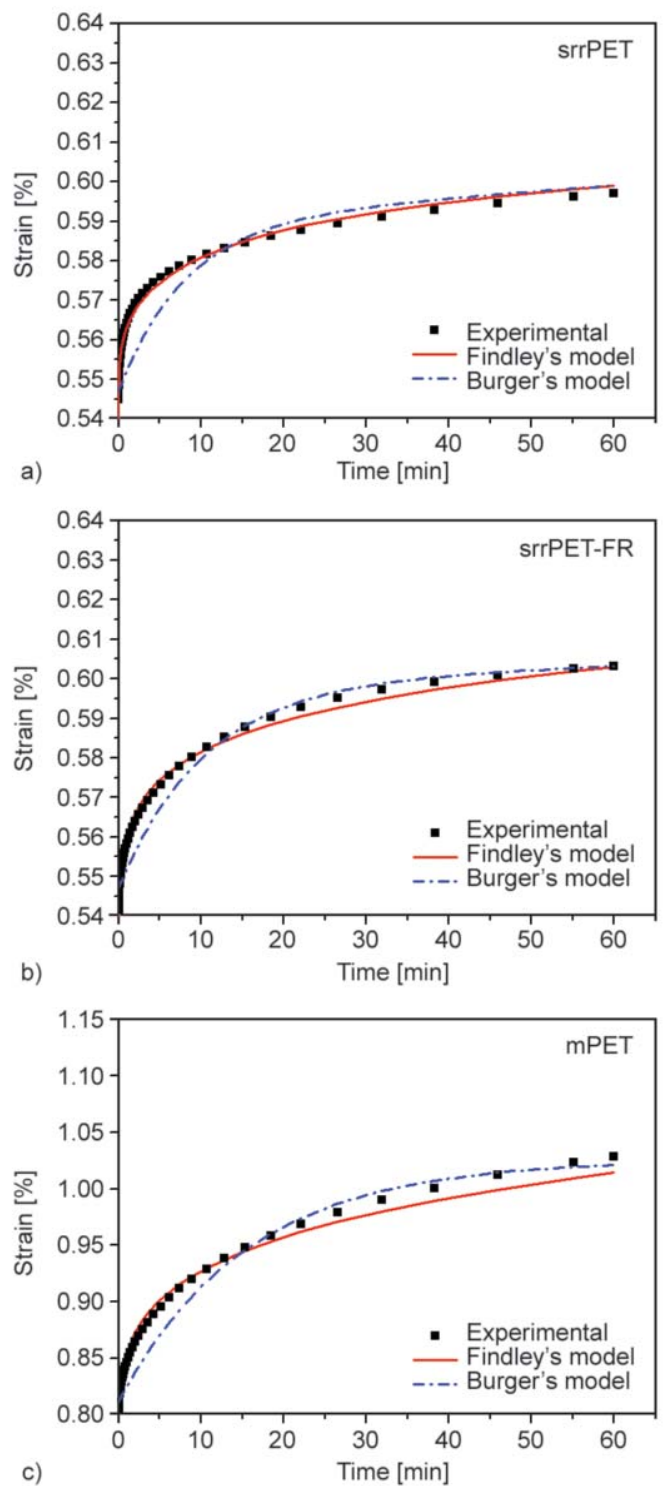

Figure 4. Short-term creep responses of the (a) srrPET, (b) srrPET-FR, and (c) mPET specimens fitted using the Findley's and Burgers model

be used to fit the experimental data for the studied materials at ambient temperature. Since mPET exhibited more viscous behavior, Findley's model underestimated its creep strain, which resulted in a deviation from the corresponding experimental curve at creep times greater than $20 \mathrm{~min}$. Findley's model produced a better fit than the Burgers model; however, it also underestimated the viscous behavior of

Table 1. Parameters of the Findley's and Burgers models obtained for srrPET composites and mPET

\begin{tabular}{|l|c|c|c|c|c|c|}
\hline & \multicolumn{2}{|c|}{ Findley's model } & \multicolumn{4}{c|}{ Burgers model } \\
\cline { 2 - 7 } & $\boldsymbol{A}$ & $\boldsymbol{n}$ & $\begin{array}{c}\boldsymbol{E}_{\mathbf{1}} \\
{[\mathbf{M P a}]}\end{array}$ & $\begin{array}{c}\boldsymbol{E}_{\mathbf{2}} \\
{[\mathbf{M P a}]}\end{array}$ & $\begin{array}{c}\boldsymbol{\eta}_{\mathbf{1}} \\
{[\mathbf{M P a} \cdot \mathbf{s}]}\end{array}$ & $\begin{array}{c}\boldsymbol{\eta}_{\mathbf{2}} \\
{[\mathbf{M P a} \cdot \mathbf{s}]}\end{array}$ \\
\hline srrPET & 0.0408 & 0.1011 & 2742 & 350 & 323974 & 230719 \\
\hline srrPET-FR & 0.0422 & 0.1215 & 2688 & 290 & 162057 & 181454 \\
\hline mPET & 0.0514 & 0.2074 & 1849 & 70 & 61274 & 65328 \\
\hline
\end{tabular}


mPET (the Burgers model was unable to perfectly fit the creep testing data since the short-term creep experiments did not demonstrate the three main creep regions corresponding to elastic response, viscoelastic response, and viscous creep deformation) $[26,28]$.

\subsection{Long-term creep behavior}

The TTSP approach was used to predict the longterm creep behavior of srrPET composites from the results of short-term creep testing experiments conducted at different temperatures. Figure 5 shows the creep strain curves obtained for srrPET and MPET at temperatures ranging from 40 to $160^{\circ} \mathrm{C}$. The measured creep strain increased with increasing temperature due to the extension and relaxation of PET molecular chains. However, rPET inhibit mPET polymer chain motion because of their improved thermostability compared to that of the mPET polymer matrix. When the temperature increases, the long chained molecules absorb more energy and become increasingly active and less able to withstand deformation. Therefore, as expected, higher temperatures accelerated the creep response of the srrPET composites. The structures of the srrPET composites are presumed to change; not only would viscous slippage of the molecular chains occur, but interfacial slippage between the sPET-FR and the mPET-FR would also take place. The creep strain of srrPET composites at $40{ }^{\circ} \mathrm{C}$ was $0.54 \%$ and did not significantly change at temperatures below $T_{\mathrm{g}}$. When the specimen temperature exceeded $T_{\mathrm{g}}$, the viscoelastic deformation of the tested samples apparently increased with increasing temperature. Therefore, the results of short-term creep testing allow superimposing the obtained strain curves onto the master curve (using the shift factors),

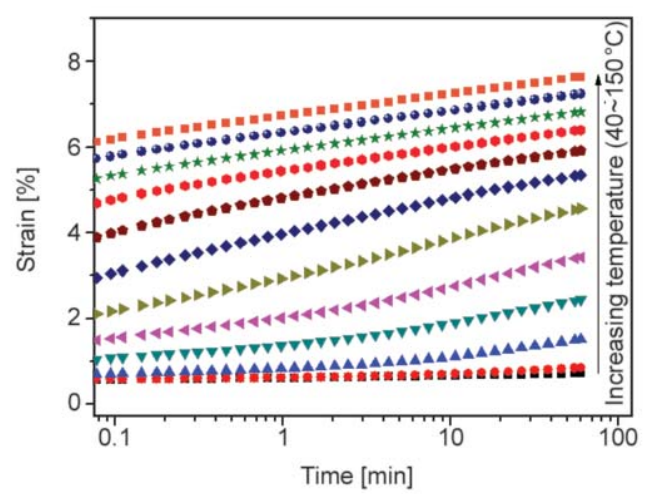

Figure 5. Creep responses of the srrPET specimen at elevated temperatures plotted on the logarithmic time scale which represents the long-term creep behavior of the srrPET specimens.

Calculation of shift factors assuming a constant value of the activation energy $\left(E_{\mathrm{a}}\right)$ was performed, which represented the only unknown parameter. Thus, the $E_{\mathrm{a}}$ of the glass transition relaxation corresponds to the energy barrier that must be overcome to initiate the molecular motions causing the transition [36]. The magnitude of $E_{\mathrm{a}}$ was calculated using the obtained frequency dependence of $T_{\mathrm{g}}$ (the utilized method was described earlier in Section 3.1). Table 2 lists the $T_{\mathrm{g}}$ values obtained for srrPET composites and $\mathrm{mPET}$ at different frequencies between 1 and to $40 \mathrm{~Hz}$ and scanning rate of $3{ }^{\circ} \mathrm{C} / \mathrm{min}$. Using Equation (4), the plot of frequency (on the natural log scale) versus the reciprocal $T_{\mathrm{g}}$ was obtained (see Figure 6), and its slope was determined. The $E_{\mathrm{a}}$ values calculated for the glass transition relaxation of srrPET, srrPET-FR, and mPET were equal to 354.5, 335.5, and $319.5 \mathrm{~kJ} / \mathrm{mol}$, respectively. The obtained magnitudes were substituted into Equation (3) to determine the shift factors for the studied materials (Figure 7a).

Table 2. Glass transition temperatures $\left[{ }^{\circ} \mathrm{C}\right]$ of the srrPET, srrPET-FR, and mPET specimens obtained at different frequencies

\begin{tabular}{|c|c|c|c|}
\hline $\begin{array}{c}\text { Frequency } \\
{[\mathbf{H z}]}\end{array}$ & srrPET & srrPET-FR & mPET \\
\hline 1 & 69.28 & 68.88 & 67.34 \\
\hline 5 & 71.03 & 70.87 & 68.87 \\
\hline 10 & 72.61 & 72.46 & 71.28 \\
\hline 15 & 73.84 & 73.86 & 72.31 \\
\hline 20 & 74.68 & 75.21 & 73.54 \\
\hline 25 & 75.62 & 76.23 & 74.25 \\
\hline 30 & 76.01 & 76.67 & 75.01 \\
\hline 35 & 76.77 & 76.83 & 75.43 \\
\hline 40 & 77.73 & 77.10 & 76.34 \\
\hline
\end{tabular}

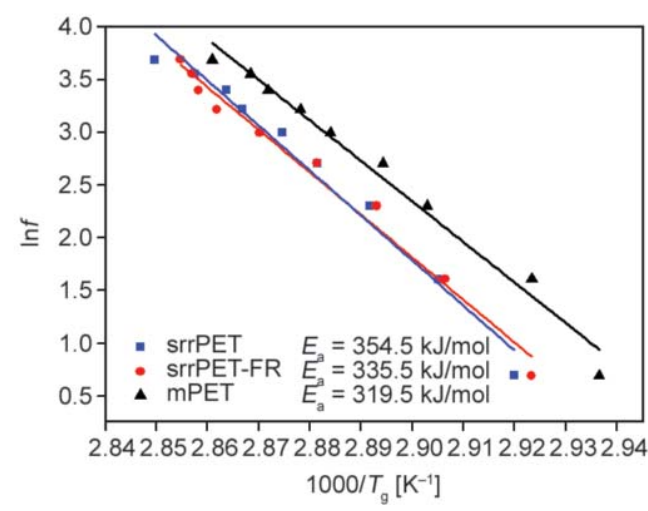

Figure 6. Natural logarithms of frequency plotted as functions of the reciprocal $T_{\mathrm{g}}$ for the srrPET and $\mathrm{mPET}$ specimens 
Finally, the long-term creep strain curve (master curve) was plotted for srrPET composites at a reference temperature of $40^{\circ} \mathrm{C}$ by shifting all curves depicted in Figure 5 in the right direction using the shift factors determined from Figure 7a (see Figure 7b).

The results displayed in Figure $7 \mathrm{~b}$ indicate that srrPET exhibits the lowest creep strain, srrPET-FR shows a slight increase in strain, and $\mathrm{mPET}$ is characterized by the highest strain. Hence, the creep behavior of thermoplastics such as PET can be significantly improved by their self-reinforcement. The effects produced by the interface between the reinforcing fibers and the matrix can be evaluated by comparing those of the srrPET (strong interaction) and srrPET-FR (poor interaction) specimens. A slight increase in the creep strain observed for srrPET-FR demonstrated that the presence of reinforcements represents the dominant factor, and that the interfacial properties deteriorate the creep behavior of a material only slightly. The estimated strains of srrPET composites after creep testing durations of 1 and 5 years were 1.21 and $1.52 \%$, while the corresponding magnitudes obtained for $\mathrm{mPET}$ were 4.12 and $5.47 \%$, respectively. Therefore, srrPET composites exhibit better creep resistance as compared to that of mPET, which can be attributed to the reinforcing effect of rPET fibers.

To evaluate the creep behavior of a sample under longterm conditions, the concept of the modulus reduction was introduced using the following Equation (5) [16]:

Modulus reduction $[\%]=\left(1-\frac{\varepsilon_{0}}{\varepsilon(t)}\right) \cdot 100$

The modulus reductions estimated for 1 year creep testing of srrPET and MPET are listed in Table 3. The obtained results show that srrPET exhibited the lowest modulus reduction of $60 \%$, which corresponded to the longest lifetime. The addition of flame retardant increased the modulus reduction value to $65 \%$, while its highest magnitude obtained for mPET was $85 \%$. As compared to the modulus reductions of srPP ranging between 71.5 and $87 \%$ [31-33] and those of natural fiber composites (between 65 and 75\%) [23$28]$, the studied srrPET composites exhibited superior creep resistance.

\subsection{Open-hole creep behaviors}

To study the effect of the hole drilling on the storage modulus and creep performance of srrPET composites, flexural creep experiments were performed on specimens containing open circular holes with different sizes (the resulting plots of the storage modulus versus temperature are shown in Figure 8). The storage modulus of srrPET obtained in the glassy state decreased with increasing hole size from 3.2 to $2 \mathrm{GPa}$, indicating that hole drilling reduced the composite resistance to elastic deformation. The results of short-term flexural creep testing of the srrPET specimens containing open holes are shown in Figure 9. They revealed that the measured creep strain was dominated by elastic strain, while the contributions of viscoelastic and viscous creep strains were significantly smaller. The creep strains of srPET composites increased with increasing hole size. Thus, the elastic strain and final strain values obtained for srrPET after $1 \mathrm{~h}$ of testing were 0.53 and $0.60 \%$, while the corresponding magnitudes measured for the srrPET specimen with a $4 \mathrm{~mm}$ hole were equal to 0.66 and $0.73 \%$, and for the srrPET specimen with a $8 \mathrm{~mm}$ hole, the values were 0.84 and $0.95 \%$, respectively. The observed increase in the creep strain after $1 \mathrm{~h}$ was independent of the hole size and was equal to

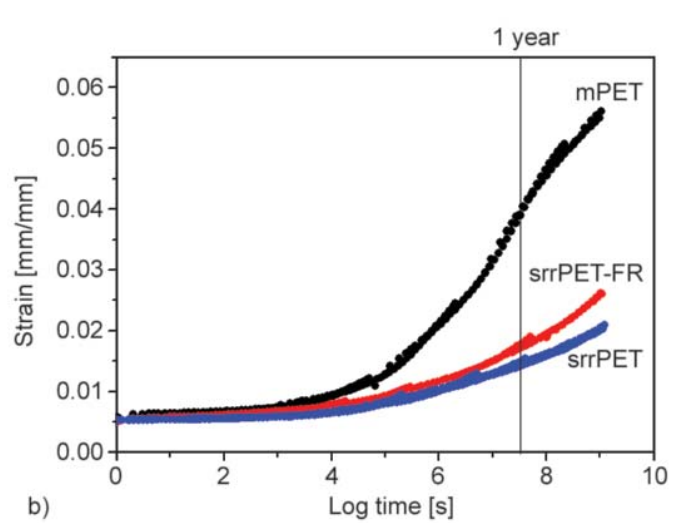

Figure 7. (a) Shift factors obtained for the srrPET and mPET specimens at various temperatures. (b) A comparison of the curve fits performed by using the Arrhenius equation and master curves plotted for the srrPET and mPET specimens. 

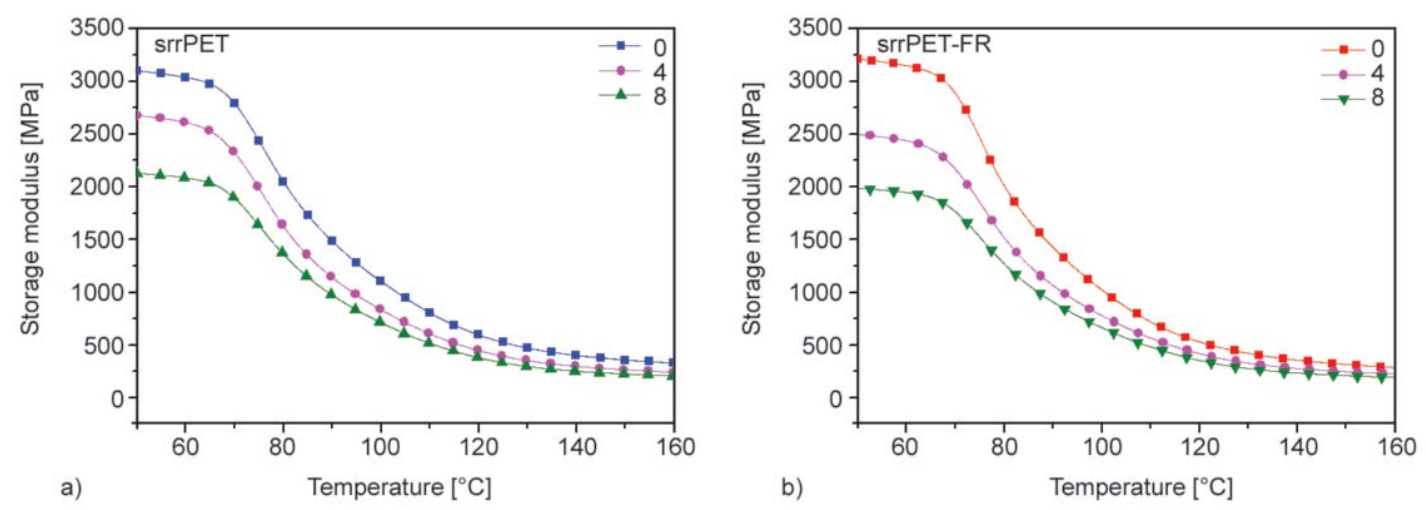

Figure 8. Storage moduli of the srrPET (a) and srrPET-FR (b) specimens with different hole sizes plotted as functions of temperature
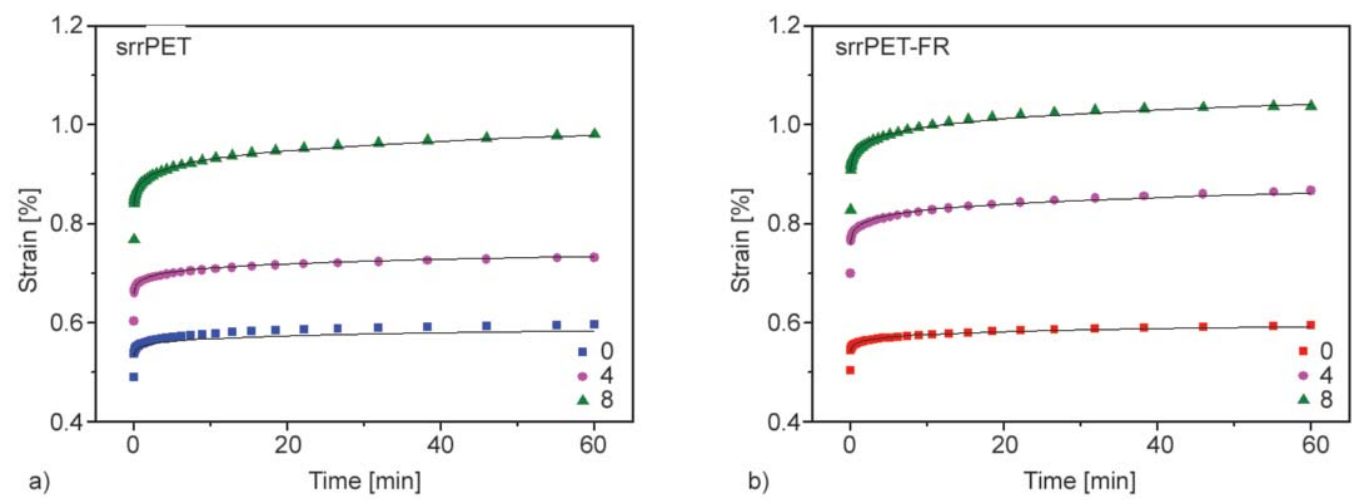

Figure 9. Short-term creep responses of the srrPET (a) and srrPET-FR (b) specimens with different hole sizes fitted using Findley's model

$0.07 \%$ for all srrPET samples. The short-term creep behavior of the srrPET specimens with open holes was evaluated using the Findley's model (its fitting parameters $A$ and $n$ are listed in Table 3 ). The values of $A$ and $n$ increased with increasing hole size (it should be noted that the time-independent factor $A$ represented elastic creep deformation, while the factor $\mathrm{n}$ was related to the time effect). The obtained results confirmed that the creep strain of the studied composites was dominated by elastic strain. The values of $n$ increased only slightly, indicating that the

Table 3. Parameters of Findley's model, strain, and modulus reduction obtained after 1 year of creep testing of the srrPET specimens with different hole sizes

\begin{tabular}{|l|c|c|c|c|c|}
\hline \multirow{3}{*}{ Material } & $\begin{array}{c}\text { Hole } \\
\text { size } \\
{[\mathbf{m m}]}\end{array}$ & $\boldsymbol{A}$ & $\boldsymbol{n}$ & $\begin{array}{c}\text { Strain } \\
\text { after } \\
\mathbf{1} \text { year } \\
{[\%]}\end{array}$ & $\begin{array}{c}\text { Modulus } \\
\text { reduction } \\
{[\%]}\end{array}$ \\
\hline \multirow{3}{*}{ srrPET } & 0 & 0.0408 & 0.1011 & 3.90 & 85 \\
\cline { 2 - 6 } & 4 & 0.0535 & 0.1091 & 1.32 & 60 \\
\cline { 2 - 6 } & 8 & 0.0639 & 0.1158 & 1.61 & 65 \\
\hline \multirow{3}{*}{ srrPET-FR } & 0 & 0.0422 & 0.1215 & 2.00 & 68 \\
\cline { 2 - 6 } & 4 & 0.0567 & 0.1283 & 1.64 & 65 \\
\cline { 2 - 6 } & 8 & 0.0720 & 0.1321 & 2.03 & 69 \\
\hline
\end{tabular}

hole size was almost insensitive to the time-dependent creep deformation and thus demonstrating the structural integrity and notch insensitivity of srrPET composites.

TTSP was also utilized to predict the long-term creep behavior of the srrPET specimens containing open holes (the same shift factors obtained from Figure 8a were used during testing because the main material remained unchanged). As a result, the short-term creep curves were plotted for srrPET composites with different hole sizes at various testing temperatures. After applying the shift factors, the master curves for the studied hole-containing materials were obtained (Figure 10). In contrast to the results of short-term creep testing, the long-term creep strains of the holedrilled srrPET composites increased with increasing hole size. However, these materials continued to exhibit superior creep resistance (as compared to that of mPET). The modulus reduction values determined from Figure 10 for the hole-drilled srrPET specimens (see Table 3) were used for a quantitative comparison. Thus, the modulus reductions obtained for srrPET composites with 4 and $8 \mathrm{~mm}$ holes were equal to 65 and $68 \%$, whereas those for the srrPET-FR 

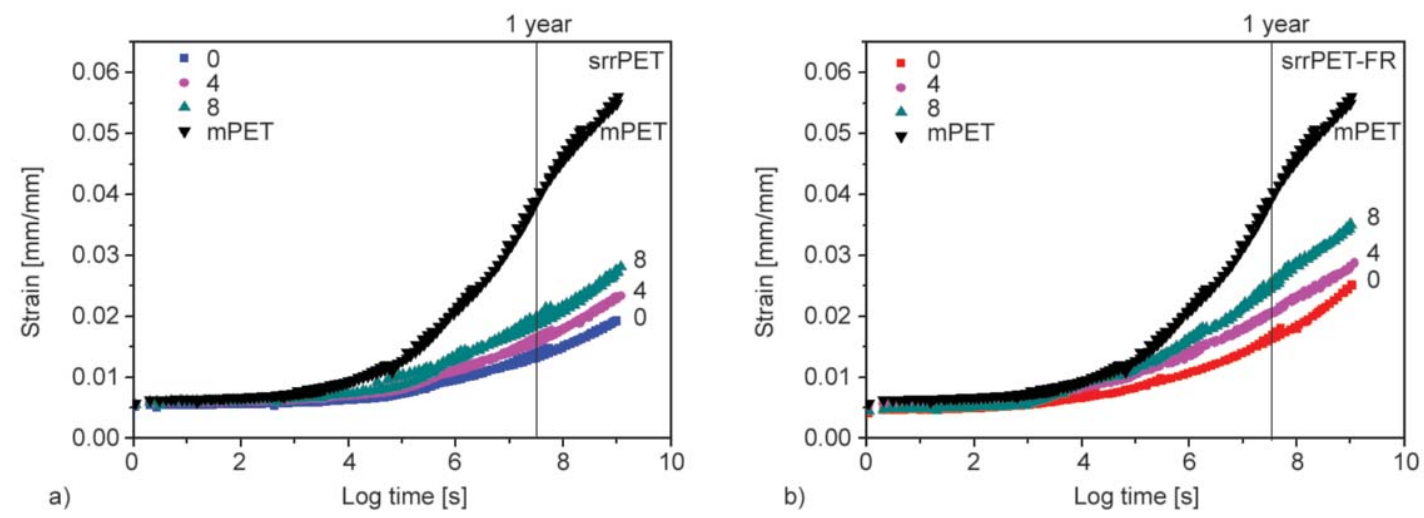

Figure 10. Master curves plotted for the srrPET (a) and srrPET-FR (b) and mPET specimens with different hole sizes

specimens were 69 and $74 \%$, respectively. The modulus reduction observed for the hole-drilled srrPET was still lower than that of mPET (85\%), demonstrating the notch insensitivity [14] and superior creep resistance of srrPET composites. Although hole drilling may deteriorate the elastic performance of srrPET, it does not destroy its structural integrity.

\section{Conclusions}

Self-reinforced PET composites with and without flame retardant were subjected to short-term flexural creep testing, and their long-term creep behavior was evaluated using the Arrhenius-type time temperature superposition principle. The obtained results of experimental creep testing were analyzed using the Findley's viscoelastic and Burgers four-element models, and the main conclusions can be summarized as follows.

1) Self-reinforcement of PET polymer significantly improves its resistance to creep deformation due to the introduction of highly rigid recycled PET fibers.

2) A slight increase in the creep strain observed for flame retarded self-reinforced PET composites demonstrated that the presence of reinforcements represented the dominant factor affecting its creep behavior, while the effect produced by the interface between the fibers and the PET matrix was negligible.

3) srrPET composites exhibited the lowest modulus reduction followed by those of flame retarded selfreinforced PET composites, and pure PET resin, which indicated the superior creep resistance of srrPET composites.

4) The long-term creep strain of the hole-drilled srrPET composites increased with increasing hole size; however, their creep resistance was still higher than that of pure PET resin. The modulus reduction observed for the hole-drilled Self-reinforced PET composites specimens was lower than that of pure PET resin, which demonstrated the notch insensitivity and superior creep resistance of the former materials.

\section{Acknowledgements}

The work was partially supported by the Ministry of Science and Technology of Taiwan, ROC (grant numbers: MOST 105-2221-E-011-160 and MOST 105-2221-E-011-161).

\section{References}

[1] Fakirov S.: Nano- and microfibrillar single-polymer composites: A review. Macromolecular Materials and Engineering, 298, 9-32 (2013). https://doi.org/10.1002/mame.201200226

[2] Fakirov S.: Nano-/microfibrillar polymer-polymer and single polymer composites: The converting instead of adding concept. Composites Science and Technology, 89, 211-225 (2013).

https://doi.org/10.1016/j.compscitech.2013.10.007

[3] Kmetty Á., Bárány T., Karger-Kocsis J.: Self-reinforced polymeric materials: A review. Progress in Polymer Science, 35, 1288-1310 (2010).

https://doi.org/10.1016/j.progpolymsci.2010.07.002

[4] Karger-Kocsis J., Bárány T.: Single-polymer composites (SPCs): Status and future trends. Composites Science and Technology, 92, 77-94 (2014).

https://doi.org/10.1016/j.compscitech.2013.12.006

[5] Bocz K., Toldy A., Kmetty Á., Bárány T., Igricz T., Marosi G.: Development of flame retarded self-reinforced composites from automotive shredder plastic waste. Polymer Degradation and Stability, 97, 221-227 (2012). https://doi.org/10.1016/j.polymdegradstab.2011.12.029

[6] Zhang J. M., Reynolds C. T., Peijs T.: All-poly(ethylene terephthalate) composites by film stacking of oriented tapes. Composites Part A: Applied Science and Manufacturing, 40, 1747-1755 (2009). https://doi.org/10.1016/j.compositesa.2009.08.008 
[7] Zhang J. M., Peijs T.: Self-reinforced poly(ethylene terephthalate) composites by hot consolidation of bicomponent PET yarns. Composites Part A: Applied Science and Manufacturing, 41, 964-972 (2010). https://doi.org/10.1016/j.compositesa.2010.03.012

[8] Abraham T. N., Wanjale S. D., Bárány T., Karger-Kocsis $\mathrm{J} .:$ Tensile mechanical and perforation impact behavior of all-PP composites containing random PP copolymer as matrix and stretched PP homopolymer as reinforcement: Effect of $\beta$ nucleation of the matrix. Composites Part A: Applied Science and Manufacturing, 40, 662668 (2009).

https://doi.org/10.1016/j.compositesa.2009.03.001

[9] Fakirov S., Duhovic M., Maitrot P., Bhattacharyya D.: From PET nanofibrils to nanofibrillar single-polymer composites. Macromolecular Materials and Engineering, 295, 515-518 (2010).

https://doi.org/10.1002/mame.200900387

[10] Kannan T. G., Wu C. M., Cheng K. B.: Effect of different knitted structure on the mechanical properties and damage behavior of flax/PLA (poly lactic acid) double covered uncommingled yarn composites. Composites Part B: Engineering, 43, 2836-2842 (2012).

https://doi.org/10.1016/j.compositesb.2012.04.047

[11] Jiang J., Chen N.: Preforms and composites manufactured by novel flax/polypropylene cowrap spinning method. Journal of Composite Materials, 46, $2097-$ 2109 (2012). https://doi.org/10.1177/0021998311430155

[12] Wu C. M., Lin P. C., Tsai C. T.: Fabrication and mechanical properties of self-reinforced polyester composites by double covered uncommingled yarn. Polymer Composites, 37, 3331-3340 (2016).

https://doi.org/10.1002/pc.23531

[13] Romhány G., Wu C. M., Lai W. Y., Karger-Kocsis J.: Fracture behavior and damage development in self-reinforced PET composites assessed by located acoustic emission and thermography: Effects of flame retardant and recycled PET. Composites Science and Technology, 132, 76-83 (2016). https://doi.org/10.1016/j.compscitech.2016.06.014

[14] Wu C. M., Lai W. Y.: Mechanical and open hole tensile properties of self-reinforced PET composites with recycled PET fiber reinforcement. Journal of Applied Polymer Science, 133, 43682/1-43682/8 (2016). https://doi.org/10.1002/app.43682

[15] Chen J. C., Wu C. M., Pu F. C., Chiu C. H.: Fabrication and mechanical properties of self-reinforced poly(ethylene terephthalate) composites. Express Polymer Letters, 5, 228-237 (2011).

https://doi.org/10.3144/expresspolymlett.2011.22

[16] Goertzen W. K., Kessler M. R.: Creep behavior of carbon fiber/epoxy matrix composites. Materials Science and Engineering: A, 421, 217-225 (2006).

https://doi.org/10.1016/j.msea.2006.01.063
[17] Sá M. F., Gomes A. M., Correia J. R., Silvestre N.: Creep behavior of pultruded GFRP elements - Part 1: Literature review and experimental study. Composite Structures, 93, 2450-2459 (2011). https://doi.org/10.1016/j.compstruct.2011.04.013

[18] Dasappa P., Lee-Sullivan P., Xiao X.: Temperature effects on creep behavior of continuous fiber GMT composites. Composites Part A: Applied Science and Manufacturing, 40, 1071-1081 (2009).

https://doi.org/10.1016/j.compositesa.2009.04.026

[19] Pegoretti A., Kolarik J., Slouf M.: Phase structure and tensile creep of recycled poly(ethylene terephthalate)/ short glass fibers/impact modifier ternary composites. Express Polymer Letters, 3, 235-244 (2009). https://doi.org/10.3144/expresspolymlett.2009.30

[20] Houshyar S., Shanks R. A.: Mechanical and thermal properties of toughened polypropylene composites. Journal of Applied Polymer Science, 105, 390-397 (2007). https://doi.org/10.1002/app.25034

[21] Kim K. J., Yu W. R., Harrison P.: Optimum consolidation of self-reinforced polypropylene composite and its time-dependent deformation behavior. Composites Part A: Applied Science and Manufacturing, 39, 1597-1605 (2008).

https://doi.org/10.1016/j.compositesa.2008.06.005

[22] Houshyar S., Shanks R. A., Hodzic A.: Tensile creep behaviour of polypropylene fibre reinforced polypropylene composites. Polymer Testing, 24, 257--264 (2005). https://doi.org/10.1016/j.polymertesting.2004.07.003

[23] Houshyar S., Shanks R. A.: Tensile properties and creep response of polypropylene fibre composites with variation of fibre diameter. Polymer International, 53, 1752-1759 (2004). https://doi.org/10.1002/pi.1569

[24] Acha B. A., Reboredo M. M., Marcovich N. E.: Creep and dynamic mechanical behavior of $\mathrm{PP}$-jute composites: Effect of the interfacial adhesion. Composites Part A: Applied Science and Manufacturing, 38, 1507-1516 (2007).

https://doi.org/10.1016/j.compositesa.2007.01.003

[25] Xu Y., Wu Q., Lei Y., Yao F.: Creep behavior of bagasse fiber reinforced polymer composites. Bioresource Technology, 101, 3280-3286 (2010).

https://doi.org/10.1016/j.biortech.2009.12.072

[26] Wang W. H., Huang H. B., Du H. H., Wang H.: Effects of fiber size on short-term creep behavior of wood fiber/ HDPE composites. Polymer Engineering and Science, 55, 693-700 (2015).

https://doi.org/10.1002/pen.23935

[27] Yang T. C., Wu T. L., Hung K. C., Chen Y. L., Wu J. H.: Mechanical properties and extended creep behavior of bamboo fiber reinforced recycled poly(lactic acid) composites using the time-temperature superposition principle. Construction and Building Materials, 93, 558563 (2015).

https://doi.org/10.1016/j.conbuildmat.2015.06.038 
[28] Georgiopoulos P., Kontou E., Christopoulos A.: Shortterm creep behavior of a biodegradable polymer reinforced with wood-fibers. Composites Part B: Engineering, 80, 134-144 (2015).

https://doi.org/10.1016/j.compositesb.2015.05.046

[29] Tamrakar S., Lopez-Anido R. A., Kiziltas A., Gardner D. J.: Time and temperature dependent response of a woodpolypropylene composite. Composites Part A: Applied Science and Manufacturing, 42, 834-842 (2011). https://doi.org/10.1016/j.compositesa.2011.03.011

[30] Nuñez A. J., Marcovich N. E., Aranguren M. I.: Analysis of the creep behavior of polypropylene-woodflour composites. Polymer Engineering and Science, 44, 1594-1603 (2004).

https://doi.org/10.1002/pen.20157

[31] Izer A., Bárány T.: Effect of consolidation on the flexural creep behaviour of all-polypropylene composite. Express Polymer Letters, 4, 210-216 (2010). https://doi.org/10.3144/expresspolymlett.2010.27
[32] Banik K., Abraham T. N., Karger-Kocsis J.: Flexural creep behavior of unidirectional and cross-ply all-poly (propylene) (PURE ${ }^{\circledR}$ ) composites. Macromolecular Materials and Engineering, 292, 1280-1288 (2007). https://doi.org/10.1002/mame.200700180

[33] Banik K., Karger-Kocsis J., Abraham T.: Flexural creep of all-polypropylene composites: Model analysis. Polymer Engineering and Science, 48, 941-948 (2008). https://doi.org/10.1002/pen.21041

[34] Findley W. N., Lai J. S., Onaran K.: Creep and relaxation of nonlinear viscoelastic materials with an introduction to linear viscoelasticity. Elsevier, Amsterdam (1976).

[35] Chen J., Gardner D. J.: Dynamic mechanical properties of extruded nylon-wood composites. Polymer Composites, 29, 372-379 (2008).

https://doi.org/10.1002/pc.20400

[36] LaPlante G., Lee-Sullivan P.: Moisture effects on FM300 structural film adhesive: Stress relaxation, fracture toughness, and dynamic mechanical analysis. Journal of Applied Polymer Science, 95, 1285-1294 (2005). https://doi.org/10.1002/app.21353 